\title{
Police Stress, Mental Health, and Resiliency during the COVID-19 Pandemic
}

\author{
Received: 5 June 2020 / Accepted: 12 June 2020 / \\ Published online: 26 June 2020 \\ (C) Southern Criminal Justice Association 2020
}

John Stogner ${ }^{1}$ (D) Bryan Lee Miller ${ }^{2} \cdot$ Kyle McLean $^{2}$

\begin{abstract}
The COVID-19 pandemic created social upheaval and altered norms for all members of society, but its effects on first responders have been particularly profound. Law enforcement officers have been expected to coordinate local shutdowns, encourage social distancing, and enforce stay-at-home mandates all while completing the responsibilities for which they are already understaffed and underfunded. The impact of the COVID-19 pandemic on officer stress, mental health, resiliency, and misconduct is explored drawing insight from reactions to the HIV epidemic over two decades earlier and the terrorist attacks of September 11, 2001. COVID-19 policing is hypothesized to serve as a significant stressor for officers and compound the general and organizational stress associated with the occupation. Avenues for providing officer support are discussed and recommendations for research into the phenomenon presented.
\end{abstract}

Keywords COVID-19 $\cdot$ Policing $\cdot$ Police $\cdot$ Law enforcement $\cdot$ Stress $\cdot$ Coronavirus

Policing is one of the most mentally taxing occupations contending with long and often rotating shifts, threats of violence, increased need for hypervigilance, and a lack of public support creating chronic stress (Hartley, Burchfiel, Fekedulegn, Andrew, \& Violanti, 2011; McCraty \& Atkinson, 2012; Paoline, 2003; Terrill, Paoline, \& Manning, 2003). As a result, law enforcement officers suffer from mental health problems at a rate greater than the general population even before dealing with added pandemic challenges, stress, and uncertainty (Hartley et al., 2011). Mental health problems among law enforcement personnel are associated with work environment, agency culture, inconsistent shift scheduling, and presumably higher exposure to

\section{John Stogner}

johnstogner@uncc.edu

1 Department of Criminology \& Criminal Justice, University of North Carolina at Charlotte, Charlotte, NC, USA

2 Department of Sociology, Anthropology \& Criminal Justice, Clemson University, Clemson, SC, USA 
traumatic events and subsequent post-traumatic stress disorder (PTSD; Brown \& Campbell, 1990; Collins \& Gibbs, 2003; Crank \& Caldero, 1991; Marmar et al., 2006). Consequently, law enforcement officers are more likely than the general population to suffer from depression, experience familial strife, misuse alcohol, and attempt suicide (Wang et al., 2010; Rees \& Smith, 2008; Menard \& Arter, 2013). These negative coping behaviors can hinder officer resiliency in the wake of traumatic incidents. They also have the potential to impair reactions to large-scale social and occupational changes induced by anomic conditions which place increased demands for a wide range of law enforcement services.

The sudden disruption of American society resulting from the COVID-19 pandemic is particularly concerning as it may impact police mental health at a time when they are most needed by the public. Law enforcement officers are not immune from the stress that COVID-19 placed on the general population. In fact, they are likely more heavily impacted as they are one of the "essential workers" that must continue to work and respond to calls for service while others shelter at home. As first responders normally and more so during the shutdown, they may experience increased stress risk due to the prolonged threat of virus exposure and stay-at-home ordinance compliance enforcement. Compounding normal risk factors, COVID-19 social distancing policies have resulted in numerous changes and alterations in protocols including requirements to wear personal protection equipment (PPE), altered patrolling routines, and changes to shift schedules and work hours that drive workplace stress. In addition to the direct impact of the COVID- 19 pandemic on officer wellbeing, law enforcement is likely to experience increased highstress encounters with individuals suffering from mental health problems aggravated by fear of contagion, economic uncertainty, resource shortages, and isolation. First responders may react more strongly to a crisis such as COVID-19 due to their responsibility for maintaining public safety, risk of exposure through interactions with the community, and the concern of exposing family members to the virus.

\section{COVID-19's Likely Impact on Officer Stress Extrapolated through Historical Context}

COVID-19 refers to the infectious disease that results from a novel coronavirus that was not identified until an outbreak in Wuhan, China in December of 2019. Pathogens in the coronavirus family may cause acute respiratory infections and difficulty breathing. The illness resulting from the novel coronavirus, COVID-19, is marked by respiratory symptoms (congestion, cough, difficulty breathing) as well as hyperthermia and exhaustion. COVID-19 effects seem to be exacerbated by underlying conditions such as hypertension, diabetes, and cardiopathy. At the time of writing, COVID-19 has infected over 6 million people including 1.7 million in the United States (WHO, 2020). COVID-19 has spread quickly as interpersonal transmission can occur through respiratory droplets and contaminated surfaces. As a result, many jurisdictions have enacted stay-at-home orders, limited work to essential functions, and created social distancing directives. These decisions have seemingly slowed the spread of COVID-19; still, over 350,000 have died due to complications connected to the illness including over 100,000 Americans (WHO, 2020). These figures are projected to double by the end of July, 2020. 
The 2020 COVID-19 pandemic impact on policing strategies and mental health in criminal justice settings is matched in magnitude by only a limited number of events in the past century. As research on COVID-19 and the interrelated public policy and health ramifications of both the disease and the coordinated response is still in its infancy, reference to earlier crises that significantly altered law enforcement practices, namely the start of the HIV epidemic in the 1980s and the attacks of September 11, 2001, provide reference context. These previous large-scale distressing events affected perceptions of safety, job stress, and standard practices of law enforcement officers including the need to address traumatized members of the public. The COVID-19 pandemic is likely to also affect these domains, but the form of those effects may be distinct per the unknown nature and already comparatively longer duration of the pandemic than some prior national traumatic events.

One of the closest analogies to the current law enforcement climate is the spread of HIV in the 1980s. While HIV is manageable today, uncertainty reigned three decades ago. Law enforcement officers were tasked with enforcing policies in an environment of misunderstood risk. Flavin (1998) describes a pervasive fear of HIV among officers who generally overestimated their occupational risk. A perceived inability to manage HIV risk intensified fear (Jermier, Gaines, \& McIntosh, 1989). Officers of that era had limited and evolving information about transmission (Leinen, 1993), much like those policing during the height of COVID-19. Perhaps law enforcement officers today are not dissuaded from assisting injured citizens proximate to the prior fear of contracting HIV, but encounters with the public no doubt generate similar stress as reports already describe officers dying after contracting COVID-19. Thompson and Marquart's (1998) study indicated that HIV risk was a significant stressor among law enforcement officers although training diminished these concerns while Robinson, Sigman, and Wilson (1997) suggest it may have contributed to PTSD among officers. Assuming policing prior to heightened understanding of HIV serves as a valid analogy for law enforcement stress during COVID-19, it is clear that an exploration of how COVID-19 has affected officer stress and behavior is warranted. Similarly, officers may benefit from increased resources directed towards assisting them and their family with stress management during this time of crisis.

The terrorist attacks of September 11, 2001 also may serve as reference for how broader world issues impact officer stress throughout the country. Following the attack on the World Trade Center and the Pentagon, numerous police and other first responders risked their safety and rushed into unknown danger to assist the public. Similar results from samples of these heroes indicate mental health concerns resulted from this service. One-third of the officers responding from the Arlington County Police Department reported significantly heightened post-traumatic stress disorder (PTSD) symptoms years after responding to the Pentagon (Robbers \& Jenkins, 2005). Over $20 \%$ of New York responders reported PTSD symptoms with $5.4 \%$ reaching diagnostic thresholds over four years after the attack; $40 \%$ of these officers reported needing mental healthcare (Pietrzak et al., 2012). Suicidal ideation among officers also increased (Violanti, Castellano, O'Rourke, \& Paton, 2006). However, that day's event affected stress levels of officers beyond these locations. Studies demonstrate increases in police stress in other cities in the year following the incident as well as a shifting of perceived major sources of stress. Whereas data collected prior to $9 / 11$ reported that harming a civilian and the safety of fellow officers were prime concerns/ 
stresses, data from similar respondents collected a year after 9/11 indicated that police felt dealing with terrorist or hate groups and being prepared for riots were foremost among their concerns (Stevens, 2004). Further, the attacks prompted numerous organizational changes within police forces which exacerbated stress (Marks \& Sun, 2007).

Terrorist threats may not on the surface appear an apt comparison for a viral pathogen like COVID-19, but the psychological connection is clear. Both are invisible dangers; officers can no more see the intention of citizens than they can SARS-CoV-2 which causes COVID-19. In each case, threats can come from anywhere - the person with the bulging backpack standing in front of the museum could be carrying a bomb or the person clearing their throat could be showing the initial signs of a COVID-19 infection. Each concern requires hypervigilance as one exposure, or one missed threat, can be deadly for a large number of citizens. In each situation, there has been distrust for organizations providing data. Police viewed limited information from federal sources as a source of stress following the 9/11 attacks (Stevens, 2004) and the integrity of the Centers for Disease Control and Prevention and the World Health Organization have been challenged during the COVID-19 pandemic. This analogy also provides context to expect that the COVID-19 pandemic may disproportionately affect stress levels of women in law enforcement as large gender differences in police stress resulted from 9/11 (Bowler et al., 2010). It also suggests that strong social integration may minimize occupational stress and mental health issues resulting from COVID-19 as officers that were better connected to others were less affected by terrorist threats and showed greater resiliency (Schwarzer, Bowler, \& Cone, 2014).

\section{Policing in the COVID-19 Pandemic: Occupational Stressors}

Reactions of the law enforcement community to COVID-19 thus far have been near ubiquitous. Efforts were made to procure and utilize protective personal equipment (PPE) and officers have encouraged and enforced social distancing. Depending on the size of the agency and the available resources, police departments have marked off briefing rooms with spots for officers to sit six feet away from each other or even held briefings outside - where the virus is thought to be less likely to spread. Discretion when dealing with the public is at a premium as is avoiding physical proximity in situations where a response or arrest can be avoided. For example, many urban agencies have instructed officers to conduct fewer traffic stops and avoid unnecessary interpersonal interactions (Mohler et al., 2020). Overall, calls for service may have slightly decreased during the height of the COVID-19 pandemic (Campedelli, Aziani, \& Favarin, 2020; Mohler et al., 2020), but certain offenses have been increasingly reported including vandalism and domestic violence (Mohler et al., 2020) as well as theft of medical equipment (Hulett, 2020). Though service calls may have decreased per shelter-in-place guidelines, the burden on individual officers ostensibly increases as indicated by over 1000 virus cases within the NYPD - 15\% of the workforce reporting being sick and unavailable to serve (ABC, 2020).

In addition to carrying the burden for stricken colleagues, COVID-19 presented officers with novel and exacerbated stressors. First, they were expected to implement new policies to ensure social distancing while stay-at-home directives were challenged on political, economic, and legal grounds. As the agents of new and unpopular 
restrictions, officers may have experienced additional anxiety and disapproval from the citizenry served (Shirzad, Abbasi Farajzadeh, Hosseini Zijoud, \& Farnoosh, 2020). Second, they were required to adapt existing practices to "virus reality." Community and offender programs, service call responses, and patrol practices had to be adapted to limit exposure and ensure enough officers remained healthy to maintain public safety. These adaptations, oft centered on limiting interpersonal contact, potentially created cognitive dissonance in instances where officers avoided serving the public or making a minor arrest to limit their own exposure. Third, agencies clearly suffered from shortages in PPE. Panic following COVID-19's spread cleared masks, gloves, sanitizer and other needed supplies from inventory. Officers likely experienced stress through the limited availability of PPE or by using items they understood to be needed by the general public. The lack of these resources, per the extension of the logic of a general resource shortfall, is more problematic in disadvantaged rural areas. Fourth, the COVID-19 pandemic itself was a traumatic event, presenting consistent risk of bodily harm and requiring officers to be increasingly hypervigilant of their own environment. The daily exposure to stress, safety protocols, and social distancing policies may have limited their capacity to engage in positive coping strategies.

The threat of COVID-19 and the challenges of social distancing policies presents a particular problem for small rural law enforcement agencies. These groups have fewer resources and are less likely to employ individuals that specialize in health policy, mental health management, and information distribution to guide both the workforce and population it serves through the pandemic. Large, urban agencies have partnered together to share information during the coronavirus pandemic through the Police Executive Research Forum's (PERF) Daily COVID-19 Reports (https://www. policeforum.org/coronavirus\#daily) and resources like the American Society for Evidence-Based Policing's (ASEBP) COVID Portal for sharing response strategies and new policies (https:/www.americansebpcovid.org/). While rural agencies can also gain access to these resources, their smaller size means they are less likely to have officers with connections to these organizations.

Law enforcement training in rural agencies is also likely less dynamic and adaptive to developing needs. Larger workforces allow training that has smaller incremental costs and there is specialization of activities. Thus, an emerging issue, like the need to adapt to a global viral pandemic is likely to put a disproportionate strain on officers in rural jurisdictions with ritualistic agency culture. Their organizational size limits leverage for acquiring resources such as personal protective equipment and tools to enforce social distancing protocols. Further, it may hinder the resiliency and the adaptation of existing programs to the evolving needs of citizens during windows of social upheaval. The pandemic paired with limited training and resources to deal with its consequences are likely to have an extensive and longterm impact on rural law enforcement officer mental health.

While rural jurisdictions may lack the resources and specialized work forces that can assist with reactivity to a threat like COVID-19, urban areas are disproportionately the site of protests, riots, and social unrest during a period of extreme stress. Tension related to stay-at-home orders escalated throughout the early stages of the pandemic with many citizens becoming concerned about the financial repercussions of lockdowns. Large groups descended on state capitals and other large cities to protest for the opportunity to work and earn an income. This created a demand for law enforcement to manage potentially violent groups without curtailing their First Amendment rights. 
Ensuring safety during large scale protest is generally a stressful challenge but is enhanced during a viral pandemic. Law enforcement was responsible for both providing a presence to deter violent and unruly behavior, but also to encourage social distancing and use of face masks and other protective wear-an unprecedented dual responsibility. Further, racial tension towards police escalated during the pandemic due to the deaths of Breonna Taylor and George Floyd at the hands of officers in Kentucky and Minnesota, respectively. Urban centers drew crowds protesting, rioting, and looting; officers in large agencies became both the focus of acrimony and responsible for ensuring unruly crowds' safety from a viral threat.

\section{Proliferation and Extension of COVID-19 Stress in Law Enforcement}

While not intended to describe the behavior of police, Slocum's (2010) exploration of behavioral continuity in the context of strain theories provides a framework for how the COVID-19 may influence officer stress, mental health, and performance long after any vaccine is introduced. First, Slocum (2010) describes the negative impact of past and existing stressors on individuals' ability to deal with new stressors and challenges. A reasonable inference would be that officers dealing with stressors associated with COVID-19 response are less ready to deal with new stressors. While COVID-19 policing stressors may impair officers' functions from a psychological perspective, the omnipresent stress of policing during an uncertain pandemic is likely to impact neurotransmitter and stress hormone levels resulting in increased susceptibility to stress and overreactions (e.g., Fishbein, 2001). Put simply, dealing with evolving regulations, ever-changing departmental policies, enforcing unpopular shutdowns, and the fear of contracting COVID-19 likely diminish officers' ability to deal with the numerous other stresses that characterize their profession.

Second, Slocum's (2010) stress proliferation arguments can be applied to COVID19 policing in both primary and secondary forms. Dealing with COVID-related demands and uncertainty itself presents as a source of stress, but also clearly exacerbates other job stressors that may impact mental health. Dealing with an unruly citizen becomes increasingly challenging due to social distancing expectations and protective gear. Another example of primary proliferation is COVID-19 affecting shift schedules and work rotations in an atypical manner (meant to minimize the chance of numerous officers being infected at once), when inconsistent work schedules already serve as a significant source of officer stress and fatigue. Secondary stress proliferation also likely occurs in situations where COVID-19 policing precautions affect family life. Officers exposed to the public may have chosen to avoid extended contact with family in case they contracted COVID-19 and be limited in their options to cope with stress in the manner they did prior to COVID-19. Thus, COVID-19 policing potentially impacts officer stress in domains outside of the work, intensifying the potential need for stress management and mental health assistance.

\section{Police Productivity in the Midst of a Pandemic}

While COVID-19's largest impact on policing has likely been on organizational protocols and officer mental health, the stress endured during the pandemic has likely 
had a deleterious effect on officer productivity, efficiency, and ability to perform social outreach functions. Moon and Jonson (2012) indicate that officer stress is inversely linked to job commitment - those that experience more job-related stress are less committed to their position as a law enforcement officers. Wolfe, Rojek, Manjarrez, and Rojek (2018) similarly found that uncertainty over the future of policing was a significant factor in understanding officers' job satisfaction. An extended increase in stress, as well as uncertainty surrounding the future of policing, during the COVID-19 pandemic likely impacted the dedication and resiliency of current officers. Further, job stressors directly impact performance indicators (Shane, 2010) suggesting that COVID-19 may have impaired some officers' ability to respond to calls for service. It remains to be seen whether the pandemic will result in increased officer turnover, but as extant research points to stressors facilitating burnout among officers (Russell, Cole, \& Jones III, 2014), it is likely jurisdictions will employ a less experienced workforce in the upcoming years.

Acknowledging the potential relationship between COVID-related officer stress and productivity, performance is further impacted by safety protocols that limit interaction or simply require officers' attention. Each moment that officers spend stocking, preparing, donning, and discarding personal protective equipment is a moment that is not spent completing essential functions. Equipment may impair field of vision, breathing, and grip on objects hindering officer functions. The expectation that uniformed officers will encourage social distancing and enforce lockdown directives requires time that distracts from other obligations; as such, performance measures such as clearance rates may suffer during the COVID-19 pandemic.

\section{COVID-19 Stress and Police Misconduct}

In addition to reduced police productivity, we are likely to see more incidents of police misconduct. By the nature of the occupation, police officers must uphold high standards of ethical behavior, but police misconduct is associated with increases in organizational stressors (Bishopp, Worrall, \& Piquero, 2016). These are likely to increase during the uncertainty and increased protocols during a pandemic. Furthering these challenges, police officers are the face of the government on the street. That is, they are likely the only direct representative of the government and its laws that many people interact with. As community tensions have increased and citizens voice greater resistance to stay-at-home mandates and business restrictions, police officers are forced to deal with implementing unpopular rules that they did not create.

One of the more stressful roles assumed by law enforcement is crowd control in an unplanned and unrehearsed situation. While a planned political function with detailed organization may not introduce large amounts of stress on officers, a more chaotic event without clear boundaries, drills, and for which citizens have no awareness of normative procedures is likely to be seen as extremely stressful (Garbarino et al., 2012). Sporting celebrations, unforeseen weather emergencies, and riots each present challenges that accumulate stress on officers and may encourage or facilitate misconduct. The stress-creating unknown and unrehearsed nature of these events was compounded by the lack of precedent - protests of social distancing and shutdown orders are unlike any other of the modern era. Groups assembling to vie for their right to interact with others were violating orders that regulated assembly and group size. Additionally, due 
to the stated position of these protests, most ignored best practices for reducing the spread of COVID-19 by not leaving six feet of distance between themselves and police officers, as well as not wearing a mask. In one iconic photo, a protestor at the state capitol in Michigan leans in and screams in the face of two Michigan State Police officers. It is easy to see how these officers would be stressed that in performing their duties, they were potentially exposing themselves to the virus. Police were forced to adapt to protect protestors from their compatriot's viral loads.

While large protests were common in larger cities, they also appeared in other areas across the country in the form of challenges to governmental directives (e.g., nonessential business remaining open/reopening in opposition to state mandates). Further exacerbating officer stress was the aforementioned protests of racial injustice directly following those focused on governmental intrusion into business. Just as general strain theory predicts that individuals placed under severe strain will respond with maladaptive coping mechanisms such as crime, officers facing continued stress through repeated protests and potential viral exposure, coupled with serving in the low control environment that characterized by rioting, may engage in maladaptive deviant behaviors in the form of police misconduct. Officers targeted as a result of other officers' behavior or governmental lockdowns are likely to feel angry and act to protect themselves.

Some organizational strains can be reduced by administrators, but increased community tension, and the fear and uncertainty related to COVID-19 creates additional stress and opportunities to engage in problematic coping behaviors and misconduct. Police misconduct has been the focus of researchers and policy makers prior to COVID-19 and additional efforts to reduce stress and increase training to promote ethical conduct have already been implemented by a number of agencies.

For example, there are some police training programs designed to combat ethical violations and promote officer wellbeing. To address widespread corruption and misconduct the New Orleans Police Department (NOPD) created the Ethical Policing is Courageous (EPIC) peer intervention program which encourages active bystandership with the goal of reducing negative behaviors and officer misconduct in the NOPD (Aronie \& Lopez, 2017; Morgan, Murphy, \& Horwitz, 2017; Staub, 2019). The main focus of the training is to encourage active bystander peers to step in when officers first start down a path of deviance (Staub, 2018; Staub, 2019). This intervention is intended to encourage officers to stop their fellow officer from engaging in misconduct that could potentially cost their job and erode public trust in the police department. Additionally, the training also focuses on wellbeing to encourage prosocial coping mechanisms and active bystandership can help to reduce alcohol abuse and other unhealthy habits resulting in a positive impact on officer's mental health. Although this training is promising and could help stem misconduct and increased stress caused by a pandemic, it has yet to be evaluated.

\section{Support of Officer Stress and Mental Health during a Pandemic}

Several initiatives have been undertaken to improve officer mental health which continues to be a funding priority for the National Institute of Justice. Among the promising avenues for improving mental health are programs that target organizational 
fairness. Officers routinely report treatment at the hands of command staff and immediate supervisors as a primary source of stress in policing (Brown \& Campbell, 1990; Collins \& Gibbs, 2003; Crank \& Caldero, 1991). Furthermore, in the face of increasing uncertainty, improved treatment at the hands of supervisors can improve police officers' job satisfaction (Wolfe et al., 2018). Thus, programs that improve leaderships' ability to increase fairness in the workplace should have positive effects on officers' mental health and job satisfaction.

Other methods of improving officer mental health include programs that encourage officers to positively cope through activities such as yoga and meditation (e.g., Tactical Yoga, Yoga for First Responders, and Cop to Yoga). Other programs have encouraged officers to talk to therapists regarding the mental strain of policing. However, these programs are often criticized as the hyper-masculine culture of policing discourages officers to seek external help. Accordingly, programs that target positive scoping skills from within the department or through peer networks is often recommended. As officers continue to deal with the stress of potential viral exposure of the coming months, it will be important for departmental leadership to reduce stress as much as possible, and for officers to identify positive coping strategies.

\section{Officer Resiliency and Returning to Pre-Pandemic Baselines}

Resilience is the ability to withstand, adapt to, and recover from adversity and stress and return to a positive state of mental health and well-being through coping strategies (U.S. Department of Health \& Human Services, 2015). Resiliency requires a holistic approach to wellness with a focus on the body, mind, and spirit (Goerling, 2012). Police officers are often exposed to a variety of life-threatening experiences including natural disasters, accidents, fires, and violent crimes (Arnetz, Nevedal, Lumley, Backman, \& Lublin, 2009). These events can have a detrimental impact on first responders and result in mental health problems and PTSD (Hartley et al., 2011). Even more challenging, if the traumatic circumstance isn't a singular event, but daily reinforced occupational stress over time due to a prolonged crisis, resiliency becomes a sustained process to try and maintain healthy prosocial behaviors.

There is evidence that police training has the potential to promote resilience and reduce stress. For example, in an experimental design, police training prior to critical incident police work simulations found through biomarkers and self-report evaluations that officers who received prior training had significantly less negative mood, less heart rate reactivity, a larger increase in antithrombin, and better performances than those without prior training (Arnetz et al., 2009). Although this training showed a physical reduction in stress and benefits in the short run, long term benefits were not assessed.

COVID-19 will have long lasting impacts on society and police departments will likely have to permanently alter some policing protocols as a result. As people start getting out in public more, police departments will need to reestablish community relationships and develop strategies to deal with individuals who have been economically impacted and address increased mental health issues in the general population. A strong focus on community policing and crisis intervention training will be essential in successful post-pandemic policing. 


\section{Moving Forward: Quantifying COVID-19 Effects and Providing Officer Support}

A global crisis like the COVID-19 pandemic undoubtedly affected law enforcement practices and the mental health of law enforcement officers. As such, it is critical to quantify the scope of these impacts in order to justify and properly target the provision of resources that allow agencies and individuals to weather the storm. Further, an understanding of COVID-19 effects will enable a more informed response to future crises in order to retain law enforcement effectiveness and avoid detrimental effects on law enforcement mental health. While COVID-related precautions are being labeled "the new normal," it is imperative that steps be taken to ensure that pandemic worsened job stress levels not become "the new normal" for law enforcement officers.

We offer a number of recommendations for researchers to help understand this phenomenon. First, the impact of the COVID-19 pandemic on officer stress must be quantified. As the events of 2020 were unforeseen, it was impossible for researchers to have planned a longitudinal study of the pandemic's effects beginning before its onset. As such, it is necessary to replicate data collected on law enforcement stress, mental health, and performance before the pandemic. Care must be taken to ensure a comparable sample or to draw data from the same sampling frame. Within such studies it is not only relevant to determine if an event increased law enforcement stress, but also if it shifted the source of job-related stressors (e.g., Stevens, 2004). Additionally, stress in other life domains, as well as healthy and unhealthy coping, should be quantified as major stressors as the COVID-19 response may proliferate into other areas of officers' lives (Slocum, 2010).

Second, identification of officer characteristics and behaviors linked to successful coping following this traumatic event is key. Certain psychological traits or skills developed during trainings related to mental health may have empowered more positive responses to stressors. The provision of similar training programs may assist other officers in dealing with future unforeseen pandemics while awareness of traits linked to successful stress responses may provide insight in hiring processes. More importantly, the identification of characteristics linked to less effective management of COVIDrelated stress may assist departments in directing resources towards their officers in most need of mental health services.

Third, studies should focus on agency responses to the COVID-19 pandemic. While numerous studies of this type are likely underway, the general focus is likely on physical health issues and response to calls for service. An understanding of how law enforcement groups looked to protect their own members' mental health during a time of crisis is needed so that the actions of successful agencies can be replicated by others across the country.

In addition to researching the impact of COVID-19 on officer wellbeing, this information should be utilized to adapt and develop future training protocols to help first responders and police officers. In the wake of this unprecedented situation, it is likely that many agencies were caught unprepared for the mental stress that their officers would experience. However, with scientists already discussing second waves and future outbreaks, now is the time to prepare officers for these situations. In our view, this requires two primary paths forward for policing agencies: (1) departments must focus on being logistically prepared for viral outbreaks through the stockpiling of PPE and the development of emergency plans for how to police during a pandemic and 
(2) departments must provide officers with training to improve skills for positive coping in the face of extreme stress. As noted above, uncertainty can be a major source of stress. By ensuring that the department is logistically prepared for an outbreak with PPE and plans for altering policing strategies in future pandemics, officers should experience less uncertainty and less stress. Furthermore, while it is impossible to completely remove stress from these types of situations, providing training on positive coping skills should help officers to deal with the stress they do face without the side effects of increased burnout, poor mental health, and unhealthy behaviors such as alcoholism.

\section{References}

ABC 2020. ABC News. Retrieved from: https://abc7ny.com/nypd-coronavirus-deaths-nyc-news/6065991/

Arnetz, B. B., Nevedal, D. C., Lumley, M. A., Backman, L., \& Lublin, A. (2009). Trauma resilience training for police: Psychophysiological and performance effects. Journal of Police and Criminal Psychology, 24(1), 1-9.

Aronie, J., \& Lopez, C. E. (2017). Keeping each other safe: An assessment of the use of peer intervention programs to prevent police officer mistakes and misconduct, using New Orleans' EPIC program as a potential national model. Police Quarterly, 20(3), 295-321.

Bishopp, S. A., Worrall, J., \& Piquero, N. L. (2016). General strain and police misconduct: The role of organizational influence. Policing: An International Journal of Police Strategies \& Management.

Bowler, R. M., Han, H., Gocheva, V., Nakagawa, S., Alper, H., DiGrande, L., \& Cone, J. E. (2010). Gender differences in probable posttraumatic stress disorder among police responders to the 2001 world trade center terrorist attack. American Journal of Industrial Medicine, 53(12), 1186-1196.

Brown, J. M., \& Campbell, E. A. (1990). Sources of occupational stress in the police. Work \& Stress, 4, 305-318.

Campedelli, G. M., Aziani, A., \& Favarin, S. (2020). Exploring the effect of 2019-nCoV containment policies on crime: The case of los Angeles. arXiv preprint arXiv:2003.11021.

Collins, P. A., \& Gibbs, A. C. C. (2003). Stress in police officers: A study of the origins, prevalence and severity of stress-related symptoms within a county police force. Occupational Medicine, 53, 256-264.

Crank, J. P., \& Caldero, M. (1991). The production of occupational stress in medium-sized police agencies: A survey of line officers in eight municipal departments. Journal of Criminal Justice, 19, 339-349.

Fishbein, M. (2001). Project SAFER: Using theory to identify critical targets for HIV prevention interventions.

Flavin, J. (1998). Police and HIV/AIDS: The risk, the reality, the response. American Journal of Criminal Justice, 23(1), 33-58.

Garbarino, S., Magnavita, N., Chiorri, C., Brisinda, D., Cuomo, G., Venuti, A., \& Fenici, R. (2012). Evaluation of operational stress in riot and crowd control police units: A global challenge for prevention and management of police task-related stress. Journal of Police and Criminal Psychology, 27(2), 111-122.

Goerling, R. J. (2012). Police officer resilience and community building. ASBBS Proceedings, 19(1), 394.

Hartley, T. A., Burchfiel, C. M., Fekedulegn, D., Andrew, M. E., \& Violanti, J. M. (2011). Health disparities in police officers: Comparisons to the U.S. general population. Int J Emerg Mental Health, 13, 211-220.

Jermier, J. M., Gaines, J., \& McIntosh, N. J. (1989). Reactions to physically dangerous work: A conceptual and empirical analysis. Journal of Organizational Behavior, 10(1), 15-33.

Leinen, S. H. (1993). Gay cops. Rutgers University Press.

Marks, D. E., \& Sun, I. Y. (2007). The impact of 9/11 on organizational development among state and local law enforcement agencies. Journal of Contemporary Criminal Justice, 23(2), 159-173.

Marmar, C. R., McCaslin, S. E., Metzler, T. J., Best, S., Weiss, D. S., et al. (2006). Predictors of posttraumatic stress in police and other first responders. Annals of the New York Academy of Sciences, 1071(1), 1-18.

McCraty, R., \& Atkinson, M. (2012). Resilience training program reduces physiological and psychological stress in police officers. Glob Adv Health Med, 1, 42-64.

Menard, K. S., \& Arter, M. L. (2013). Police officer alcohol use and trauma symptoms: Associations with critical incidents, coping, and social stressors. International Journal of Stress Management, 20, 37-56.

Mohler, G., Bertozzi, A. L., Carter, J., Short, M. B., Sledge, D., Tita, G. E., ... \& Brantingham, P. J. (2020) Impact of social distancing during COVID-19 pandemic on crime in Indianapolis.

Moon, M. M., \& Jonson, C. L. (2012). The influence of occupational strain on organizational commitment among police: A general strain theory approach. Journal of Criminal Justice, 40(3), 249-258. 
Morgan, T. H. S., Murphy, D., \& Horwitz, B. (2017). Police reform through data-driven management. Police Quarterly, 20(3), 275-294.

Paoline, E. A. (2003). Taking stock: Toward a richer understanding of police culture. Journal of Criminal Justice, 31, 199-214.

Rees, B., \& Smith, J. (2008). Breaking the silence: The traumatic circle of policing. International Journal of Police Science and Management, 10, 267-279.

Robbers, M. L., \& Jenkins, J. M. (2005). Symptomatology of post-traumatic stress disorder among first responders to the pentagon on 9/11: A preliminary analysis of Arlington County police first responders. Police Practice and Research, 6(3), 235-249.

Robinson, H. M., Sigman, M. R., \& Wilson, J. P. (1997). Duty-related stressors and PTSD symptoms in suburban police officers. Psychological Reports, 81(3), 835-845.

Russell, L. M., Cole, B. M., \& Jones III, R. J. (2014). High-risk occupations: How leadership, stress, and ability to cope influence burnout in law enforcement. Journal of Leadership, Accountability and Ethics, 11(3), 49.

Pietrzak, R. H., Schechter, C. B., Bromet, E. J., Katz, C. L., Reissman, D. B., Ozbay, F., et al. (2012). The burden of full and subsyndromal posttraumatic stress disorder among police involved in the world trade center rescue and recovery effort. Journal of Psychiatric Research, 46(7), 835-842.

Shane, J. M. (2010). Organizational stressors and police performance. Journal of Criminal Justice, 38(4), 807818.

Shirzad, H., Abbasi Farajzadeh, M., Hosseini Zijoud, S. R., \& Farnoosh, G. (2020). The role of military and police forces in crisis management due to the COVID-19 outbreak in Iran and the world. Journal of Police Medicine, 9(2), 63-70.

Schwarzer, R., Bowler, R. M., \& Cone, J. E. (2014). Social integration buffers stress in New York police after the 9/11 terrorist attack. Anxiety, Stress \& Coping, 27(1), 18-26.

Slocum, L. A. (2010). General strain theory and the development of stressors and substance use over time: An empirical examination. Journal of Criminal Justice, 38(6), 1100-1112.

Staub, E. (2018). Preventing violence and promoting active bystandership and peace: My life in research and applications. Peace and Conflict: Journal of Peace Psychology, 24(1), 95-111.

Staub, E. (2019). Witnesses/bystanders: The tragic fruits of passivity, the power of bystanders, and promoting active Bystandership in children, adults, and groups. Journal of Social Issues, 75(4), 1262-1293.

Stevens, D. J. (2004). Origins of police officer stress before and after 9/11. The Police Journal, 77(2), 145-173.

Terrill, W., Paoline, E. A., \& Manning, P. K. (2003). Police culture and coercion. Criminology, 41, 10031034.

Thompson, R. A., \& Marquart, J. W. (1998). Law enforcement responses to the HIV/AIDS epidemic. Policing: An International Journal of Police Strategies \& Managemen.

U.S. Department of Health and Human Services. (2015). Individual resilience. Public Health and Medical Emergency Support for a National Prepared. Retrieved from http://www.phe.gov/Preparedness/planning/abc/Pages/individualresilience.aspx

Violanti, J. M., Castellano, C., O'Rourke, J., \& Paton, D. (2006). Proximity to the 9/11 terrorist attack and suicide ideation in police officers. Traumatology, 12(3), 248-254.

Wang, Z., Inslicht, S. S., Metzler, T. J., Henn-Haase, C., McCaslin, S. E., Tong, H., Neylan, T. C., \& Marmar, C. R. (2010). A prospective study of predictors of depressive symptoms in police. Psychiatry Research, $175,211-216$.

WHO, 2020 Coronavirus disease 2019 (COVID-19) Situation Report - 84 (April 13, 2020).

Wolfe, S. E., Rojek, J., Manjarrez, V. M., \& Rojek, A. (2018). Why does organizational justice matter? Uncertainty management among law enforcement officers. Journal of Criminal Justice, 54, 20-29.

Publisher's Note Springer Nature remains neutral with regard to jurisdictional claims in published maps and institutional affiliations.

John Stogner is an Associate Professor of Criminal Justice and Criminology and also of public policy at the University of North Carolina at Charlotte. His research and teaching focuses on criminological theory and substance use with a particular emphasis on novel and emerging drugs. He also explores health-related criminological issues, peer influences on delinquency, and biosocial criminology. He coauthored Emerging Trends in Drug Use and Distribution and his works have appeared in journals such as Pediatrics, Addictive Behaviors, Drug and Alcohol Dependence, and Justice Quarterly. 
Bryan Lee Miller, PhD is an Associate Professor of Criminal Justice at Clemson University and recent Fulbright Scholar at Tampere University (Finland). His work has evaluated drug abuse, co-occuring mental illnes and substance abuse, and identification of interactive criminogenic factors and risk factors. He has worked on multiple Department of Justice funded projects to develop law enforcement-led justice and mental health programs. He is Chair of the Drug \& Alcohol Research Section of the Academy of Criminal Justice Sciences and President-elect of the Southern Criminal Justice Association.

Kyle McLean, PhD is an Assistant Professor of Criminal Justice at Clemson University. Dr. McLean is also a National Institute of Justice Law Enforcement Advancing Data and Science Academic. His research interests are in policing, criminological theory, and social psychology. His recent work has been published in Justice Quarterly, Journal of Research in Crime and Delinquency, and the British Journal of Criminology. 